\title{
PENTINGNYA PENDIDIKAN MORAL DALAM PENDIDIKAN KEWARGANEGARAAN
}

Sendi Fauzi Giwangsa

STKIP Sebelas April Sumedang

sendifaurigiwangsa@gmail.com

\section{ABSTRACT}

The recent phenomenon of moral decline has become a concern for some of our people. This is marked by the many immoral behaviors that are widely reported by national television. Education is one of the tools in instilling morals in children. Both education in the family environment and formal education at school. Citizenship Education (PKn) is one of the subjects that aims to encourage morale in students. Naum in practice often learning PKn only teaches knowledge only without any more emphasis on aspects of attitude and skills. Knowledge is important because knowledge will be the basis for action. But that is not enough to instill moral in students. Strengthening is needed especially in the aspect of attitude and of course it must be practiced in everyday life so that because morals are not enough just for material knowledge but also a habit of behaving in life.

Keywords: moral education, citizenship

\begin{abstract}
ABSTRAK
Fenomena penurunan moral baru-baru ini telah menjadi perhatian bagi beberapa orang kita. Ini ditandai oleh banyak perilaku tak bermoral yang dilaporkan secara luas oleh televisi nasional. Pendidikan adalah salah satu alat dalam menanamkan moral pada anak-anak. Kedua pendidikan di lingkungan keluarga dan pendidikan formal di sekolah. Pendidikan Kewarganegaraan (PKN) adalah salah satu mata pelajaran yang bertujuan untuk mendorong semangat siswa. Namun dalam prakteknya sering belajar PKN hanya mengajarkan pengetahuan saja tanpa lebih menekankan pada aspek sikap dan keterampilan. Pengetahuan itu penting karena pengetahuan akan menjadi dasar untuk bertindak. Tetapi itu tidak cukup untuk menanamkan moral pada siswa. Penguatan diperlukan terutama dalam aspek sikap dan tentu saja harus dipraktikkan dalam kehidupan sehari-hari sehingga karena moral tidak cukup hanya untuk pengetahuan materi tetapi juga kebiasaan berperilaku dalam kehidupan.
\end{abstract}

Kata kunci: pendidikan moral, kewarganegaraan

\section{PENDAHULUAN}

Kebijakan tentang diberikannya pendidikan moral atau budi pekerti bagi para siswa pernah digaungkan beberapa tahun yang lalu. Kebijakan tersebut dipandang sebagai upaya strategis guna memperbaiki moralitas bangsa. Oleh berbagai kalangan, kondisi moralitas bangsa yang carut marut

Diterima: Januari 2018. Disetujui: Pebruari 2018. Dipublikasikan: Juni 2018 
dianggap sebagai penyebab utama timbulnya krisis multi dimensi. Sementara itu di kalangan masyarakatpun, terutama para orangtua, telah lama muncul kerisauan terhadap fenomena pendidikan yang kurang memberi perhatian pada pendidikan moral atau budi pekerti. Adalah wajar jika masyarakat kemudian menggugat tanggung jawab institusi pendidikan atas maraknya berbagai kasus kenakalan remaja, mulai dari kasus yang ringan hingga yang berat. Namun demikian, institusi pendidikan tentu bukan satu-satunya pihakyang harus dipersalahkan dalam masalah ini, sebab bagaimanapun juga sistem pendidikan tidak bebas dari sistem sosial yang lebih luas. Kebijakan tentang pendidikan moral atau budi pekerti kemudian menjadi wacana yang kontroversial, justru pada persoalan struktur. Persoalan yang muncul, apakah pendidikan moral atau budi pekerti perlu berdiri sebagai mata pelajaran tersendiri atau diintegrasikan ke dalam mata pelajaran/beberapa mata pelajaran yang telah ada.

Dalam perkembangannya, kebijakan tersebut seakan "mati suri" dalam sistem persekolahan kita. Dalam rumusan tujuan pendidikan nasional, baik dalam Undang-Undang Sistem Pendidikan Nasional yang berlaku saat ini maupun sebelumnya senantiasa dirumuskan tentang upaya pembentukan moralitas atau budi pekerti peserta didik, akan tetapi hal itu tidak pernah jelas implementasinya. Dalam ketidakjelasan sosok pendidikan moral dalam struktur kurikulum, masyarakat pada umumnya memandang Pendidikan Kewarganegaraan (PKn) sebagai representasi pendidikan moral.

\section{Pemahaman Tentang Moral}

Pemahaman tentang konsep moralitas; apa yang dimaksud dengan moralitas; adalah titik awal dari pendidikan moral (Zuchdi, 2001: 6). Secara etimologis, kata moral berasal dari kata mos dalam bahasa Latin, bentuk jamaknya mores, yang artinya adalah tata cara atau adat istiadat. Dalam Kamus Besar Bahasa Indonesia (1989 : 592), kata moral diartikan sebagai akhlak, budi pekerti, atau susila. Sementara itu, pada halaman 131, kata budi pekerti disinonimkan dengan tingkah laku, perangai, akhlak, atau watak. Dalam pembicaraan sehari-hari, moral juga sering disamakan denganetika. Dalam kajian akademik, etika adalah ilmu tentang tingkah laku yang baik dan yang buruk. Dengan kata lain, etika adalah ilmu tentang moral atau bahkan salah satu cabang filsafat, yakni filsafat moral. Dalam memahami sifat moral terdapat dua pandangan yang kontroversial, pertama adalah perspektif objektivistik, universal; dankedua adalah perspektif relativistik, 
kontekstual. Bagi pandangan pertama, moral itu bersifat objektivistik, artinya pasti dan tidak berubah. Suatu bentuk tingkah laku yang dianggap baik akan tetap dianggap baik, bukan kadang-kadang dianggap baik dan kadang-kadang dianggap buruk. Sejalan dengan pandangan ini, moral itu bersifat mutlak (absolut) dan tanpa syarat.

Sementara moralitas menurut Haydon (1999) adalah sistem dari batasan-batasan terhadap perilaku orang, yang memenuhi fungsi-fungsi sosial untuk melindungi kepentingan-kepentingan dari orang-orang lain. Sekaitan dengan itu, Haydon (1999) mengemukakan PKn sebaiknya menempatkan moralitas secara jelas sebagai suatu topik, dan karena moralitas adalah pandangan-pandangan berkompetisi - bahwa moralitas adalah persoalan dari pilihan pribadi, yang Tuhan berikan, moralitas juga adalah konvensi sosial, dan karena itu, moralitas harus didiskusikan. Bok (2006) mencatat, meskipun saran-saran akan etika terapan sudah biasa, etika terapan jarang diwajibkan. Sebagai hasil, mayoritas dari peserta didik lulusan sekolah tanpa menerima pelajaran dalam penalaran moral atau dalam mata pelajaran yang dibutuhkan untuk menyiapkan mereka sebagai warga negara yang banyak mengetahui dalam demokrasi.

Sebagai contoh, perbuatan mencuri itu sepenuhnya merupakan perbuatan yang bertentangan dengan moral, sehingga tidak boleh dikatakan bahwa dalam keadaan tertentu, perbuatan mencuri itu dibenarkan. Moral juga bersifat universal, sehingga perbuatan yang baik akan dianggap baik di manapun dan kapanpun juga. Dengan kata lain, nilai moral itu tidak tergantung pada dimensi ruang dan waktu. Adapun pandangan kedua menganggap bahwa moral itu bersifat relatif, artinya tergantung pada konteks, kultur, situasi dan lainlain. Dengan kata lain, sifat moral itu tergantung pada dimensi ruang dan waktu. Perbuatan yang dianggap baik di suatu tempat belum tentu dianggap baik di tempat yang lain. Demikian pula perbuatanyang dianggap baik pada masa yang lalu belum tentu dianggap baik pada masa sekarang.

Munculnya kontroversi tersebut terkait dengan sejarah pemikiran intelektual Barat, yang terbagi tiga zaman, yakni pemikiran abad klasik, abad pertengahan, dan abad modern. Pengaruhnya terhadap pemikiran tentang moral, abad klasik memandang bahwa moral itu bersifat objektivistik, naturalistik, dan rasionalistik. Sementara itu pada abad pertengahan, moral itu bersifat objektivistik, supra naturalistik, dan spiritualistik. Dengan demikian, pada kedua zaman tersebut moral 
dianggap bersifat objektivistik. Perbedaannya terletak pada aspek epistemologi, yakni sumber pengetahuan tentang moral.

Isu tentang bagaimana orang mengembangkan pengetahuan dan pertimbangan moral masih merupakan hal yang penting dari literatur psikologi baik teoritis maupun empiris (Manavipour, 2012). Perkembangan moral berkaitan dengan pertumbuhan dari pada seluruh pemikiran, nilai dan emosi yang berpengaruh kuat terhadap perilaku dalam situasi-situasi etis (Eisenberg. et al, 2009, dalam Manavipour, 2012). Salah satunya komponen-komponen kognitif dari teori tahapan seperti Piaget dan Kohlberg yang juga dibicarakan secara menonjol sekali dalam literatur perkembangan moral (Lapsley, 2006, dalam Manavipour, 2012). Teori yang secara lebih khusus membahas perkembangan penalaran dan perkembangan moral adalah Teori Kohlberg tentang penalaran dan perkembangan moral (1999, dalam Dellaportas, Cooper, Leung, 2006), berpusat pada bagaimana sistem keyakinan seseorang mengarahkan resolusi dan memecahkan masalah konflik dalam kehidupan sehari-hari. Teori Kohlberg mengusulkan bahwa individu-individu mempunyai keterampilan-ketrampilan kognitif yang mampu mengidentifikasi, dan digunakan untuk memecahkan dilema-dilema etis. Keterampilanketerampilan itu, ditentukan oleh alasan-asalan yang diberikan tentang bagaimana tindakan-tindakan tertentu yang dirasa hanya secara moral atau lebih disukai. Alasan-alasan yang digunakan oleh Kohlberg untuk memberikan kontinum hierarkis yang terdiri dari 6 tahapan perkembangan moral. Tahapan tersebut secara berturut-turut mewakili tingkat lebih tinggi dari penalaran tentang definisi dan bentuk dari benar dan salah. Dasar rasional yang digunakan para individu untuk memecahkan dilema-dilema moral, memperlihatkan karakteristik-karakteristik yang memungkinkan peneliti mengklasifikasi orang sesuai dengan tahapan tertentu dari perkembangan moral (Weber, 1990, dalam Dellaportas, Cooper, Leung, 2006).

Dalam studi Kohlberg, para subyek ditanya terutama, apakah yang mereka pikiran tentang tokoh utama dalam cerita, yang akan dilakukan dan mengapa, misalnya, suatu dilema yang berjudul "Heinz dan Obat", yang melibatkan seseorang bernama Heinz dan istrinya sakit sekarat karena kanker.

Menurut pandangan abad klasik, sumber pengetahuan tentang moral adalah rasio atau akal budi. Adapun menurut pandangan abad pertengahan, standar moral yang objektif berasal dari wahyu yang dapat diketahui secara 
spiritualistik. Selain itu, abad klasik menganggap moral sebagai persoalan duniawi atau naturalistik sedangkan abad pertengahan menganggap moral terkait dengan nilai-nilai Ilahiah serta supra natural (Kurtines and Gerwitz, 1992: 8- 21). Pandangan abad modern tentang moral dipengaruhi oleh karakteristik sains modern, yakni naturalistik, empirik, dan relativistik.

Naturalistik artinya segala fenomena dipandang sebagai produk dari berbagai proses dan kekuatan alam, tanpa melibatkan hal-hal yang bersifat spiritual atau supranatural. Empirik artinya, segala hukum danteori didasarkan pada data atau hasil pengalaman inderawi. Dengan demikian konsekuensinya adalah bahwa kebenaran rasional ditempatkan di bawah kebenaran empiris. Oleh sebab itu, kebenaran suatu hipotetis yang disusun secara rasional teoritik dapat digugurkan oleh kebenaran empiris. Dengan demikian pola pikir ini menolak adanya kemungkinan untuk memperoleh pengetahuan yang objektif dan pasti, tak terkecuali pengetahuan tentang moral. Oleh sebab itu, dalam pandangan abad modern tentang moral sulit ditemukan kepastian moral (Kurtiness and Gerwitz, 1992: 26-34).

Kohlberg menghabiskan banyak waktu untuk memperbaiki dan menghaluskan teori perkembangan moralnya seperti metode-metode pentahapannya. Kohlberg kemudian mendalilkan enam tahapan teorinya ke dalam tiga kelompok tingkatan; prekonvensional, konvensional dan postkonvensional (Kohlberg, 1984, dalam Rudd, Mullane, Stoll, 2010).

Pada tahapan prekonvensional, keputusan-keputusan moral dibuat dari perspektif egosentris. Apa yang benar didasarkan pada kepatuhan terhadap aturan-aturan, karena menghindari hukuman (Tahapan 1) atau dengan mempertimbangkan pentingnya untuk memenuhi kebutuhankebutuhan dari orang-orang lain, jadi kebutuhan yang dimiliki seseorang dapat dipenuhinya (Tahap 2) . Penalaran individu-individu pada tingkat konvensional digerakkan melintasi kepentingan-kepentingan yang dimiliki diri sendiri dan lebih menaruh perhatian terhadap keanggotaan mereka dalam suatu kelompok atau masyarakat yang lebih luas (Tahap 3), bagi mereka, apa yang benar adalah didasarkan pada pemenuhan kepentingan harapan-harapan dari orang-orang lain (misalnya, teman-teman, anggotaanggota keluarga, dan otoritas dari orang). Pembuatan keputusan moral berdasarkan pada kewajiban seseorang untuk menegakkan hukum dan berkontribusi terhadap kehendak baik dari masyarakat (Tahap 4).

Sementara penalaran-penalaran pada tahapan postkonvensional, tidak hanya melakukan untuk keanggotaan mereka pada masyarakat, tetapi juga lebih penting, keyakinan setiap individu mesti melakukannya karena prinsip 
moral (Tahap 5), jadi penalaran yang dilakukan pada tahap ini adalah didasarkan kepada pendirian seseorang terhadap kewajiban untuk menegakkan 'contract' (perjanjian) dengan masyarakat. Sedankan pada tahap 6, tahapan tertinggi, apa yang benar adalah didasarkan pada prinsip-prinsip moral, bahkan jika itu bermakna melanggar hukum-hukum tertentu. Pada tahap 6 ini, Kohlberg mengemukakan bahwa prinsip moral dari keadilan adalah inti dari pembuatan keputusan moral.

Namun demikian, meskipun besar pengaruh dari penelitian Kohlberg (1981,1984, dalam dalam Rudd, Mullane, Stoll, 2010), teori pertimbangan moral dan metodologi asesmennya, tidak ada yang tidak mengritisinya. Beberapa di antaranya berkaitan dengan; a) bias gender lakilaki dalam menyatakan apakah tingkat-tingkat lebih tinggi dari pertimbangan moral (Gilligan, 1982), b) pemaknaaan dan keberadaan 6 tahapan perkembangan (Gibbs, 2003), c) konsistensi tahapan, misalnya; penggunaan tahap perkembangan moral yang sama tanpa menghiraukan situasi (Locke, 1979; Rest, 1979), d) invarians dari perurutan tahap (Locke, 1979; Rest, 1979), e) penggunaan dari asesmen berbasis produksi verbal (Rest, 1979), f) universalitas kultural (Boyes dan Walker, 1988; Locke, 1979), dan g) pandangan amat terbatas pada pertimbangan moral (misalnya, pertimbangan moral yang utama berkaitan dengan prinsip moral dari keadilan (Walker et al.,1995).

Dalam menyikapi pandangan abad modern yang merelatifkan moralitas diperlukan sikap kritis. Salah satu kelemahan literatur Barat tentang moral atau etika adalah tidak jelasnya klasifikasi moral, yang membedakan antara moral kesusilaan dan kesopanan. Berkaitan dengan kontroversi pandangan yang objektivistik dan relativistik tersebut, dapat saja keduanya diterima dengan kategori yang berbeda. Nilai-nilai moral yang bersifat objektivistik dikategorikan sebagai moral kesusilaan, seperti kejujuran, keadilan, keihlasan, tanggung jawab dan lain-lain. Adapun nilainilai moral yang bersifat relativistik dikategorikan sebagai moral kesopanan, seperti berbicara secara sopan, hormat kepada orang yang lebih tua, tidak bertamu pada jam istirahat dan sebagainya. Persoalan etis yang digolongkan sebagai kesopanan itu sering direduksi sebagai etiket.

Klasifikasi tentang moral juga dikemukakan oleh Widjaja (1985: 154), bahwa persoalan moral atau etika membicarakan tentang tata susila dan tata sopan santun. Tata susila mendorong orang untuk berbuat baik, karena hati nuraninya mengatakan baik, lepas dari hubungannya dengan orang lain. Dengan demikian nilai-nilai kesusilaan itu bersumber dari hati nurani 
manusia yang bersifat universal. Adapun tata sopan santun mendorong untuk berbuat, terutama yang bersifat lahiriah, tidak bersumber dari hati nurani, melainkan untuk sekedar menghargai orang lain dalam pergaulan. Dengan demikian nilai-nilai kesopanan bersumber dan terkait dengan konteks lingkungan sosial, budaya, dan adat istiadat. Apa yang dikemukakan oleh Widjaja tentang hati nurani yang merupakan sumber nilai-nilai kesusilaan tersebut dalam pandangan moralitas Islam dapat disebut sebagai fithrah manusia, suatu potensi nilai-nilai dasar yang suci yang dianugerahkan oleh Tuhan kepada setiap manusia, sesuai dengan kodratnya sebagai makhluk yang paling mulia. Sementara itu menurut Immanuel Kant, perintah wajib untuk dilaksanakan yang bersumber dari hati nurani itu disebut imperatif kategoris.

\section{Pendidikan Moral dalam Sistem Sekolah}

Terkait dengan wacana pendidikan moral dalam sistem pendidikan formal (persekolahan), kiranya relevan untuk diungkapkan kembali "paradigma lama" tentang pendidikan, yakni pendidikan sebagai pewarisan dan pelestarian nilai-nilai. Paradigma semacam itu dikemukakan Bourdieu dalam Karabel and Halsey (1977: 488) :

By tradisionally defining the educational system as the group of institutional or routine mechanism by means of which is operated what Durkheim calls "the conservation of a culture inherited from the past", i.e. the transmission from generation to generation of accumulated information, classical theories tend to associate the function of cultural reproduction proper to all educational system from their function of social reproduction.

Pewarisan dan pelesteraian nilai-nilai budaya warisan masa lalu tersebut terutama menyangkut nilai-nilai moral dan adat istiadat. Pada masa yang silam, pendidikan moral pada mulanya dipandang sebagai inti dan wajah pendidikan itu sendiri. Hal itu sebagaimana dikemukakan oleh Downey \& Kelly (1978: 8), From earleist times in educational theory and practice moral education has been seen as the very core of the educational process, and moral upbringing has been regarded, almost without question, as the central feature of education itself.

Paradigma pendidikan seperti itu sering dianggap kuno, konservatif, dan tidak sesuai dengan tuntutan zaman. Paradigma pendidikan modern adalah pendidikan untuk perubahan, bukan untuk pemeliharaan nilai-nilai atau penjaga tradisi. Pendidikan yang fungsional adalah pendidikan yang mampu menjawab tantangan masa kini dan masa depan. Pandangan ini tak mungkin ditolak, namun tidak berarti bahwa nilai-nilai warisan masa lalu, 
seperti adat istiadat dan moral, merupakan sesuatu yang sudah usang dan harus dibuang.

Dalam hubungan ini menurut Emile Durkheim, seorang tokoh sosiologi Prancis, sekolah mempunyai tugas dan peranan yang sangat besar dalam perkembangan moral peserta didik. Pendapat ini berbeda dengan anggapan umum yang menyatakan bahwa pendidikan moral terutama merupakan hak keluarga. Menurut pendapatnya, meskipun keluarga merupakan lingkungan yang efektif untuk menumbuhkan perasaanperasaan mendasar tentang moralitas serta perasaan-perasaan dalam hubungan pribadi yang sederhana, namun keluarga bukan lembaga yang dibangun dengan tujuan mendidik anak untuk dapat memenuhi tuntutantuntutan masyarakat. Perlu dikemukakan bahwa Durkheim membatasi moral pada apa yang disebut "moral rasional" atau tegasnya bukan prinsipprinsip moral yang diajarkan oleh agama (Taufik Abdullah \& A.C. van der Leeden, 1986: 151-152).

Pendidikan moral ternyata juga masih memperoleh perhatian di negara-negara Barat, khususnya Amerika Serikat, yang dikenal longgar dalam persoalan moral. Menurut Kirschenbaum yang dikutip oleh Zuchdi (2001: 1-2), sejak sebelum tahun 1990 telah dikembangkan pendidikan moral, yang mengajarkan nilai-nilai tradisional, dengan dukungan para orang tua, pemuka agama, guru, dan politisi. Meningkatnya perhatian terhadap pendidikan moral itu disebabkan karena ketidakmampuan negara dalam mengatasai masalah minuman keras, kriminilitas, kekerasan, disintegrasi keluarga, meningkatnya jumlah remaja yang bunuh diri dan remaja putri yang mengandung, menurunnya tanggung jawab masyarakat, tumbuhnya pertentangan rasial dan etnis, serta tidak terkendalinya jumlah skandal pada tahun 1980-an.

Kontroversi tentang penataan pendidikan moral atau budi pekerti dalam strukur kurikulum sekolah merupakan persoalan pengorganisasian kurikulum. Tegasnya, apakah dalam penataannya mengacu pada subject curriculum, berdiri sebagai mata pelajaran tersendiri, atau integrated curriculum, yang diintegrasikan ke dalam mata pelajaran lain. Pilihan kedua sejalan dengan apa yang dikemukan Downey \& Kelly (1978: 166), yang mengatakan : Most curriculum areas, such a bistory, environmental or social studies, the study of literature, bealth and sex education, the study of relegion, offer obvious occasions for the discussion of moral problems. The expressive and creative arts too can provide opportuniteis for the development of the emotional or affective components of morallity. 
Pilihan kedua semacam itu jika diterapkan dalam sistem pendidikan nasional mungkin akan menjadi "beban tambahan" bagi guru, sebab guru dan sistem persekolahan kita telah mapan dengan orientasi subject curriculum. Dengan orientasi yang telah mapan ini, kurikulum terdiri berbagai mata pelajaran yang terpisah-pisah, masing-masing berisi materi pelajaran yang dipilih dan disusun secara logis, sistematis, dan mendalam. Para guru pada umumnya membatasi tugas profesinya pada penguasaan materi dari mata pelajaran yang diampunya.

\section{Visi dan Misi Pendidikan Kewarganegaraan}

Pendidikan Kewarganegaraan (PKn) mempunyai tujuan yang khas, yakni terbentuknya warga negara yang baik (good citizen) dalam rangka nation and character building. Namun pengertian "warga negara yang baik" itu pada masa yang lalu sering diartikan sesuai dengan tafsir penguasa. Pada masa Orde Lama, konotasi warga negara yang baik adalah berjiwa "revolusioner", anti imperialime, kolonialisme, dan neo kolonialisme. Pada masa Orde Baru, konotasinya adalah warga negara yang Pancasilais, manusia pembangunan dan sebagainya.

Pada masa Orde Lama diterbitkan buku Manusia dan Masyarakat Baru Indonesia (1962), acuan pokok mata pelajaran Civic (Kewargaan Negara). Buku tersebut antara lain berisi tentang Demokrasi Terpimpin dan Ekonomi Terpimpin, Manifesto Politik (Manipol), serta pidato-pidato Presiden yang dibukukan dalam Tujuh Bahan Pokok Indoktrinasi (Tubapi). Sejak munculnya Orde Baru pada tahun 1966, isi mata pelajaran Civic versi Orde Lama hampir seluruhnya dibuang, digantikan dengan bahan-bahan baru, terutama ketatapan-ketetapan MPRS. Sejalan dengan amanat Ketetapan MPR No. IV/MPR/1973, sejak diberlakukannya Kurikulum 1975, mata pelajaran Kewargaan Negara berganti nama menjadi Pendidikan Moral Pancasila (PMP). Dengan berlakunya Ketetapan MPR No. II/MPR/1978 tentang P-4, materi pelajaran PMP didominasi oleh materi P-4. Pada masa itu, tidak jarang guru-guru PMP sering "kehabisan bahan", sebab materi P-4 tidak jelas isi dan struktur keilmuannya. Sejalan dengan Ketetapan MPR No.XVIII/MPR/1998 yang mencabut Ketetapan MPR No. II/MPR/1978, maka materi P-4 secara resmi tidak digunakan lagi.

Dengan coraknya yang semacam itu, Pendidikan Kewarganegaraan sering dianggap sebagai alat penguasa untuk melanggengkan kekuasaan. Adalah wajar jika muncul anggapan bahwa mata pelajaran ini lebih bersifat

Madrosatuna: Jurnal Pendidikan Guru Madrasah Ibtidaiyah 1(1) (2018) 26-40 
politis dari pada akademis dan lemah landasan keilmuannya. Kenyataan yang demikian memang sering berlaku di sejumlah negara berkembang, sebagaimana dikemukakan oleh Cogan $(1998,5)$ : Citizenship education has often reflected the interest of those in power in a particular society and thus has been a matter of indoctrination and the establishment of ideological begemony rather than of education.

Pendidikan Kewarganegaraan paradigma baru berorientasi pada terbentuknya masyarakat sipil (civil society), dengan memberdayakan warga negara melalui proses pendidikan, agar mampu berperan serta secara aktif dalam sistem pemerintahan negara yang demokratis. Print dkk (1999: 25) mengemukakan, civic education is necessary for the building and consolidation of a democratic society. Peranan warga negara yang yang lemah dan pasif harus dirubah ke arah peranan yang kuat dan partisipatif. Mekanisme pengelolaan sistem pemerintahan yang demokratis semestinya tidak bersifat top down, melainkan lebih bersifat buttom up. Jika pada masa yang lalu lebih ditekankan pada peranan negara dalam mengatur kehidupan warga negara, kini perlu ditekankan pada peranan warga negara dalam mengelola kehidupan bernegara. Inilah visi dan misi Pendidikan Kewarganegaraan paradigma baru (new civic education).

Restrukturisasi isi/materi merupakan bagian penting atau bahkan umumnya dianggap terpenting dalam suatu pembaharuan kurikulum. Berkaitan dengan isi Pendidikan Kewarganegaraan, Print (1999: 11) mengemukakan adanya keragaman pemahaman sebagai berikut :

For some, civic education is the study of government, constitutions, institutions, the rule of law and the rights and responsibilities citizens For others, civics is called citizenship education emphasises processes of of democracy, active citizen participation and the engagement of people in civil society. For many, the study of civic eduation includes learnings related to the institutions and systems involved in government, political heritage, democratic processes, rights and responsibilities of citizens, public administration and judicial systems.

Sementara itu Abdul Azis Wahab (2000: 5) mengemukakan sepuluh pilar demokrasi Indonesia yang harus menjadi prinsip utama pengembangan materi Pendidikan Kewarganegaraan, yaitu :

1. Konstitusionalisme

2. Keimanan dan ketaqwaan terhadap Tuhan Yang Maha Kuasa

3. Kewarganegaraan cerdas

4. Kedaulatan rakyat

5. Kekuasaan hukum 

6. HAM
7. Pembagian kekuasaan
8. Sistem peradilan yang bebas
9. Pemerintahan Daerah
10. Kesejahteraan sosial dan keadilan sosial

\section{Dimensi Moral dalam Pendidikan Kewarganegaraan}

Kompetensi yang hendak dikembangkan oleh Pendidikan Kewarganegaraan paradigma baru adalah agar siswa mampu menjadi warga negara yang berperan serta secara aktif dalam sistem pemerintahan negara yang demokratis. Untuk memiliki kompetensi seperti itu diperlukan seperangkat pengetahuan (kognitif), ketrampilan (psikomotor), serta watak (afektif). Dalam konsep Pendidikan Kewarganegaraan disebut (1) civic knowledge, (2) civic skills, dan (3) civic disposition/traits (Ace Suryadi dan Somardi, 2000: 5).

Arah pengembangan kemampuan kognitif, afektif, dan psikomotor sudah kerap kali dirumuskan dalam kebijakan pendidikan, akan tetapi tidak jelas implementasinya dalam pembelajaran. Kuatnya penekanan pada domain kognitif dan lemahnya domain afektif merupakan kecenderungan umum berbagai mata pelajaran. Dalam hubungan ini Ringness (1975: 5) mengemukakan: One finds affective behavior in any school situation -indeed, in any situation-but compared to cognitive learning, relatively little affective learning has been deliberately introduced into the curriculum.

Terkait dengan kecenderungan tersebut, kritik terhadap PMP/PKn selama ini menyangkut hasil belajar yang juga lebih bersifat kognitif, bahkan tidak jarang bersifat verbalistik. Hasil belajar yang demikian tidak sesuai dengan Pendidikan Kewarganegaraan (PKn), yang pada umumnya dianggap sebagai representasi pendidikan moral. Lebih-lebih mata pelajaran ini dahulu dalam Kurikulum 1975 maupun 1984 memang berlabel "pendidikan moral", yakni Pendidikan Moral Pancasila (PMP). Persoalan moral menyangkut sikap dan kepribadian, sehingga pembelajarannya seharusnya lebih mengembangkan aspek afektif dan konatif (dorongan untuk bertindak). Aspek kognitif tentu tidak bisa diabaikan, sebab untuk dapat bersikap dan bertindak dengan baik tentu harus didukung oleh kognisi yang baik pula.

Domain afektif adalah the internal side dari diri manusia, yang pembentukannya memerlukan proses internalisasi yang tidak mudah dan perkembangannya juga tidak dapat diamati secara langsung (non observable). 
Sebagaimana kemampuan kognitif, kualitas afektif seseorang terhadap suatu objek itu juga berjenjang. Krathwohl, Bloom, dan Masia (1964) mengemukakan tentang Taksonomi Domain Afektif yang jenjang kedalaman afeksinya secara hirarkhis meliputi (1) Receiving, (2) Responding, (3) Valuing, (4) Organization, and (5) Characterization by a value or values complex (Bloom, et al, 1981: 301-302; Ringness, 1975: 21).

Tentang aspek materinya, dimensi moral dalam Pendidikan Kewarganegaraan dikembangkan dari materi kurikulum formal Pendidikan Kewarganegaraan itu sendiri. Sebagai contoh, dari materi tentang kekuasaan hukum dikembangkan rasa kesadaran hukum, menghormati kekuasaan lembaga peradilan, tidak "main hakimjsendiri" dan sebagainya. Agar pembelajaran yang berlangsung terasa dan kontekstual, bahan dan sumber pembelajaran sebaiknya didukung oleh berbagai peristiwa hukum atau kasus yang terjadi di masyarakat sekitar. Dengan kata lain, dimensi moral dalam Pendidikan Kewarganegaraan tidak lain adalah pengembangan kemampuan afektif atau civics disposition/traits dari setiap materi pelajaran, sebagai tindak lanjut dari kemampuan kognitifnya.

Di luar kurikulum formal, guru dengan otonomi yang dimilikinya dapat menanamkan nilai-nilai moral yang dianggap penting dalam kehidupan bermasyarakat, berbangsa, dan negara. Nilai-nilai moral itu misalnya : sopan santun dalam masyarakat, penghargaan terhadap budaya bangsa, nasionalisme, rasa kemanusiaan, kejujuran, disiplin, dan berbagai bentuk tingkah laku sehari-hari. Dengan demikian, selain kurikulum formal (formal curriculum) dimungkinkan pula bagi guru untuk mengembangkan kurikulum tersembunyi (bidden curriculum). Terkait dengan bidden curriculum, menurut Belinda Charles dalam Print (1999: 133-135), The Study of Civic Awareness and Attitudes of Secondary School Pupils (CDC, 1995) dalam rekomendasinya menekankan pentingnya etos sekolah dalam menumbuhkan pertimbangan moral dan pengejaran nilai-nilai spiritual.

Berdasar hal-hal yang telah dikemukakan, problem pendidikan moral dalam Pendidikan Kewarganegaraan lebih terletak pada strategi dan metode pembelajaran, serta teknik evaluasinya. Misalnya, dari ilustrasi tentang materi kesadaran hukum, bagaimana menginternalisasikan nilai dan norma hukum, sehingga tumbuh kesadaran hukum, kepatuhan terhadap proses hukum dan sebagainya. Selanjutnya, bagaimana mengevaluasi kesadaran, kepatuhan, penghargaan dan lain-lain sebagai suatu gejala yang tidak dapat diamati secara langsung. Evaluasi tersebut tentu tidak cukup dengan paper and pencil test, melainkan perlu teknik-teknik non tes, seperti 
wawancara, observasi, pemberian tugas dan lain-lain. Dengan demikian problemnya lebih bersifat teknis.

\section{PENUTUP}

Upaya pengembangan dimensi moral dalam Pendidikan Kewarganegaraan memerlukan penyiapan calon guru yang memiliki visi dan wawasan moral. Selain pengembangan wawasan, diperlukan pula kemampuan calon guru dalam pembelajaran dan penilaian moral. Sebagaimana telah dikemukakan, baik pembelajaran maupun penilaian dalam Pendidikan Kewarganegaran selama ini masih sebatas pada kemampuan kognitif siswa. Apa yang selama ini sering dimaksudkan sebagai penilaian terhadap moralitas siswa, pada umumnya masih merupakan penilaian terhadap kognisi siswa tentang moral.

\section{DAFTAR PUSTAKA}

Abdullah, Taufik \& A.C. van der Leeden. (1986). Durkheim dan Pengantar Sosiologi Moralitas. Jakarta: Yayasan Obor Indonesia.

Amril M. (2002). Etika Islam; Telaah Pemikiran Filsafat Moral Raghib AlIsfahani. Yogyakarta: LSFK2P-Pustaka Pelajar.

Barcalow, Emmet. (1998). Moral Philosophy; Theories and Issues. Belmot,CAWashington: Wadsworth Publishing Company.

Bertens, K. (1993). Etika. Jakarta: PT Gramedia Pustaka Utama.

Bloom, Benjamin S., et al. (1981). Evaluation to Improve Learning. New York: McGraw Hill Book Company.

Boyes, M.C., and Walker,L.J., 1988. Implications of Cultural Diversity for the Universality Claims of Kohlberg's Theory of Moral Reasoning. Human Development, 31,44-59.

Cogan, John J. (1998). Citizenship for 21st Century: An International Perspective on Education. London: Cogan Page.

Dellaportas, S., Cooper, B.J., Leung, P. (2006). Measuring Moral Judgement and the Implications of Cooperative Education and RuleBased Learning. Accounting \& Finance. Volume. 46, Issue 1, p.53-70. March 2006.

De Vos, H. (1987). Pengantar Etika, alih bahasa Soejono Soemargono. Yogyakarta: Tiara Wacana.

Downey, Merial \& A.V. Kelly. (1978). Moral Education. London, New York, Hegerstown, San Fransisco, Sydney: Harper \& Row Publisher. 
Frondizi, Risieri. (2001). Pengantar Filsafat Nilai, terjemahan Cuk Ananta Wijaya. Yogyakarta: Pustaka Pelajar.

Gilligan, Carol.1977. In a Different Voice: Women's Conceptions of Self and of Morality. Harvard Educational Review Vol.47 No.4. Nopember 1977.

Gilligan, Carol. 1982. In a Different Voice: Psychological Theory and Women's Development. Cambridge, MA: Harvard University Press.

Gibbs,J.C. 2003. Moral Development \& Reality: Beyond the Theories of Koblberg and Hoffman. Thousand Oaks, CA: Sage Publications.

Hadiwardoyo, Al. Purwo. (1990). Moral dan Masalabnya. Yogyakarta: Penerbit Kanisius.

Haydon. Graham. 1999. The Moral Agenda of Citizenship Education. The School Field, Volume X, Number 34.

Held, Virginia. (1984). Etika Moral; Pembenaran Tindakan Sosial, alih bahasa Y. Ardy Handoko. Jakarta: Erlangga.

Imam Muhni, Djuretna A. (1994). Moral \& Religi Menurut Emile Durkheim \& Henri Bergson. Yogyakarta: Penerbit Kanisius.

Karabel and Halsey, editors. (1977). Power and Ideology in Education. New York: Oxford University Press.

Kohlberg, L. 1981. Essays on Moral Development: The Philosophy of Moral Development (Vol.1). San Francisco: Harper \& Row, Publishers.

Kohlberg, L.1984. Essays on Moral Development: The Philosophy of Moral Development (Vol.2). San Francisco: Harper \& Row, Publishers

Kurtiness, William M. dan Jacob L. Gerwitz. (1992). Moralitas, Perilaku Moral dan Perkembangan Moral, alih bahasa M.I. Soelaeman. Jakarta: UI Pres.

Lickona, Thomas, editor. (1976). Moral Developtment and Behavior: Theory, Research and Social Issues. New York: copyright by Holt, Rinehart, and Winston.

Locke, D. (1979). Cognitive Stages or Developmental Phases? A Critique of Kohlberg's Stage-Structural Theory of Moral Reasoning. Journal of Moral Education, 8, 168-181.

Maarif, Ahmad Syafii (2004). "Pendidikan dan Peningkatan Kualitas Moral Bangsa”, Pidato Ilmiah pada Dies Natalis XXXIX FIS Universitas Negeri Yogyakarta, 14 September 2004.

Magnis Suseno, Franz. (1987). Etika Dasar : Masalab-Masalab Pokok Filsafat Moral. Yogyakarta: Yayasan Kanisius. 
Manavipour, Davood. (2012). Iranian Students' Moral Development Scale. Educational Research and Essay. Vol.1(2), pp.15-20, April 2012.

McAshan, H.H. (1979). Competency Based Education and Behavioral Objectives. USA: Educational Technology Publication.

Mouly, George J. (1973). Psychology of Effective Teaching. New York: Holt, Rinehart and Winston, Inc.

Muchson AR. (2000). Dasar-Dasar Pendidikan Moral (Diktat Perkuliahan). Yogyakarta: Laboratorium Jurusan PPKn FIS UNY. . (2002). Etika Kewarganegaraan (Modul). Jakarta: Direktorat PLP, Ditjen Dikdasmen, Depdiknas.

- (2003). Nilai, Norma, dan Moral (Modul). Jakarta: Direktorat PLP, Ditjen Dikdasmen, Depdiknas.

Oladipo, S.E. (2009). Moral Educcation of the Child: Whose Responsibility?. Journal Social Science, 20 (2):149-156

Print, Murray et. al. (1999). Civic Education for Civil Society. London: ASEAN Academic Press.

Reimer, Joseph et. al. (1983). Promoting Moral Growth; From Piaget to Koblberg. New York \& London: Longman.

Rest, J.R.1979. Development in Judging Moral Issues. Minneapolis, MN: University of Minnesota Press.

Ringness, Thomas A. (1975). The Affective Domain in Education. BostonToronto: copyright by Little, Brown, and Company.

Rudd, Andrew., Mullane, Susan., Stoll, Sharon., (2010). Development of an Instrumen to Measure the Moral Judgments of Sport Managers. Journal of Sport Management, 2010,24, 59-83.

Walker, L.J., Pitts, R.C., Hennig, K.H., \& Matsuba, M.K.1995. Reasoning about Morality and Real-life Moral Problems, In M.Killen \& D.Hart (Eds.), Morality in Everyday life: Developmental Perspectives (pp.371-407). Cambridge, England: Cambridge

Widjaja, A.W. (1985). Pedoman Pokok-Pokok dan Materi Perkuliahan Pancasila di Perguruan Tinggi. Jakarta: Akademika Pressindo.

Zuchdi, Darmiyati. (2001). "Pendekatan Pendidikan Nilai Secara Komprehensif Sebagai Suatu Alternatif Pembentukan Akhlak Bangsa”. Makalah Seminar. Yogyakarta: Lembaga Penelitian UNY, 11 Juni 2001. 